\title{
Using YouTube in the EFL Classroom
}

\author{
Jon Watkins \\ Kwansei Gakuin University, Japan \\ Michael Wilkins \\ Kansai University of International Studies, Japan
}

\begin{abstract}
This paper addresses various ways teachers can use the video website YouTube.com (or other online streaming video websites) to teach English and stimulate learner autonomy. If students and teachers have access to the Internet, YouTube can be a valuable tool through which multiple foreign language skills can be taught. Using YouTube both inside and outside the classroom can enhance conversation, listening, and pronunciation skills. YouTube videos can also be utilized as realia to stimulate cultural lessons, enhance exposure to World Englishes, and promote authentic vocabulary development. Even reading and writing activities can be structured around YouTube videos. In-class lessons and activities will be detailed, as will homework and projects requiring the use of online streaming videos.
\end{abstract}

For EFL teachers, it is often a struggle to utilize potentially useful technology, promote student autonomy, and create stimulating lessons. If students and teachers have adequate access to the Internet, however, there is a vast online audiovisual resource generally well known to students that can function effectively in multiple ways for a variety of English classes.

The resource, YouTube.com, is an online video repository in which nearly any digital video file can be stored and exhibited free of charge. Started in February 2005, YouTube hosts videos that are cumulatively currently viewed more than 2 billion times each day ("Timeline," 2011). While issues involving copyright infringement and obscenity standards have often made the website controversial, the vast array of diverse content and its organic community interactivity make YouTube a tremendous resource for a multitude of educational endeavors.

This paper seeks to give teachers a few starting points on how the site could be used, as well as to suggest a loose framework for online video use into which SLA and CALL researchers can conduct further research. First, a brief review of existing literature will be presented, followed by descriptions of potential YouTube applications that have been implemented. The paper will conclude with a discussion of potential limitations that might come with using online video technology and suggestions for future research.

\section{Reviewing Extant Literature Through the Lens of YouTube}

The two primary benefits to using YouTube in the classroom are the exposure to authentic English as well as the promotion of a learning style that is more autonomous and student- 
centered. When students regularly use a wide variety of English media, they are achieving a degree of L2 immersion that might otherwise be unavailable outside a study-abroad program (Johnson \& Swain, 1997). Furthermore, immersion teaching and techniques to increase L2 input have generally positive effects on the language acquisition process (Mangubhai, 2005). Additionally, incorporating technology into second-language classrooms is a way for students to connect seemingly abstract foreign language concepts to their actual experiences (Wang, 2005). Finally, incorporating technology into the classroom-particularly among low-level learners - has also been shown to generate greater student autonomy and instill lifelong language learning skills (Leung, 2004).

Since YouTube's rise to Internet prominence is a fairly recent development, substantive scholarly work into the effects online video streaming can have in an EFL classroom is fairly sparse. Berk (2009) has examined the use of video clips in college classrooms and provided a detailed rationale and conceptual framework for the practice. While Berk's study is fairly extensive, its focus is across the field of education in general instead of EFL or even SLA pedagogy; nonetheless, his list of "learning outcomes" and review of neuro-cognitive research are engaging and enlightening enough to merit consideration by EFL teachers interested in incorporating video in their classrooms (2009). Aside from Berk's study, unfortunately, specific inquiry into online video use in the classroom is fairly rare. In light of the absence of such research, this section will use YouTube to reexamine some core issues commonly found in the EFL and SLA discussion on the use of online videos in the classroom.

This paper will examine an area of use of film clips and films that frequently receives scholarly attention, and then demonstrate how this area can be connected to YouTube. Shea (1995) describes a debate between ESL / EFL teachers who favor in-depth examination of film clips and those who maintain that extensive and lengthier exposure to films is more beneficial. Shea argues for the latter position--immersing students in long engagements with films and movies. With the rise of serialized YouTube stories and other streaming website episodes, or "webisodes," teachers and students who prefer more extensive exposure to films and videos in English can be satisfied with YouTube's content (Graham, 2005). Similarly, those who favor a more intensive approach can use YouTube to access a tremendous variety of famous scenes in film history. With YouTube, students and teachers could thoroughly examine any of these scenes with a deep focus on speech cadence, tonal shifts, grammatical nuance, conversational roles, or almost any other topic currently being examined in class.

Another common area of research in EFL is the question of who should be more responsible for the direction taken in learning a language: the teacher or the student? For teachers interested in promoting learner-autonomy and student-centered learning, YouTube is again quite useful.

According to Benson and Voller (1997), the term learner autonomy is generally used to suggest any combination of five ideas: first, the responsibility of language development rests primarily on the students; second, students should acquire learning skills that they can apply to any aspect of their language development that they choose; third, students should have opportunities in which they can successfully learn independently from teachers or classmates; fourth, the specific course of language development is a path students ultimately decide; fifth, students innately crave self-guided education, but their desires are regularly thwarted by their academic institutions.

Each of these points can be related to the use of YouTube. First, students can, in their own time, choose to view a YouTube clip in English, evaluate possible limitations of comprehension on their own terms, and finally choose (or choose not) to pursue further academic attention for 
that particular area. Secondly, after exposure to a YouTube clip, a fairly advanced and linguistically self-aware student can determine approximately which pronunciation and conversation skills are desired and then attempt to acquire them. Thirdly, a student can browse the millions of videos available on YouTube without needing help from any teacher or fellow student. Fourthly, if a student finds a particular kind of clip (or YouTube channel) particularly interesting or useful in language learning, he or she can freely investigate all clips that might be of a similar vein. Finally, if a student feels the material being studied in class is not useful, then an intelligent and self-guided examination into YouTube could be conducted to supplement what the student feels is being overlooked or suppressed by the educational institution.

\section{Potential Applications}

Listening and speaking. Since YouTube and other online videos are most immediately observed through sight and sound, creative teachers can easily find new ways to use them in listening and speaking or English conversation classes. This section will list a few possible activities for EFL teachers, but this list should not be considered exhaustive by any means.

- Conversation analysis: This activity is well suited for intermediate to advanced students, and it can create a heightened awareness of effective conversation techniques as well as common conversation problems that can be avoided. In the activity, students view teacher-selected clips (or browse YouTube and select clips for themselves) that demonstrate effective or ineffective conversational techniques to reinforce material taught in class. For example, students can find film or TV clips featuring conversations that suffer because of a lack of follow-up or clarification questions. Alternatively, students might search for videos in which a conversation is effective because the members are supportive by using phrases to elicit more information from each other. By searching through YouTube conversations for targeted discussion techniques, students are critically evaluating discourse and immersing themselves in English. Student effort can be assessed by the number of illustrative conversations found on YouTube and how well the conversations demonstrate concepts discussed in class. Additionally, this project can be modified into a presentation in which students share their videos with their classmates.

- Movie trailer voiceovers: This challenging listening and speaking project can help advanced students recognize their pronunciation difficulties and improve the quality of their spoken English. In the activity, students select any two-minute movie preview from YouTube. Then students transcribe the audio in the preview. After this, the video can be downloaded from YouTube and stripped of its audio track using a free software program called YouTube Downloader (http://youtubedownloader.com/). With the aid of their transcriptions, students can then record their own voices while paying close attention to mimicry and synchronization. Different students can do the voices for different characters as well as narrate the trailer. Once the recording is done, students can use Apple or Windows video editors to redub the preview. This activity involves repeated close listening to create the transcript, and then repeated recordings in which students attempt to recreate native-like cadence, intonation, and pronunciation. Assessment is based on both listening and speaking accuracy.

- Famous movie scene reenactments: This is a creative project that is best suited for intermediate to advanced learners to improve the quality of their spoken English in a very physical and dramatic way. Students can select a famous scene from a movie--the death of Jack in the film Titanic (Cameron, 1997), for example--and then reenact it, either as a 
dramatic presentation in front of the class, or in a video clip of their own. The reenactment could focus on any number of concepts discussed in class. For example, if students have been learning about sentence stress, then by doing reenactments, they would focus on (and presumably, be evaluated according to) the accuracy of sentence stress in their mimicry. Assessment is based on the quality of the reenactment, particularly in the ways it reflects speech and pronunciation concepts discussed in class.

- Vlogging: This is a regular spoken activity that can be performed by any student who has achieved even the lowest degree of conversational proficiency. The activity allows for regular and extended extemporaneous speaking practice. Vlogging is short for "video blog," and blog is short for "web log." In essence, a vlog is an online diary in video form. A number of notable vlogs have emerged on YouTube, and students can be directed to them for extensive listening practice or for any other listening lesson in which authentic English realia is needed. Of greater use is the students' regular maintenance of their own vlog. This would entail them speaking before a web-camera for a limited period of time, watching and evaluating their recorded statements before deciding to post, and then watching and listening to the vlog replies of their classmates or teacher. Due to YouTube's privacy settings, vlogs can be uploaded to YouTube in complete privacy and made available for viewing only to the student in question, the instructor, and any invited classmates. Assessment could be performed in accordance to overall student pronunciation, level of vocabulary, use of grammar, and general communicativeness.

Reading and writing. At first glance, YouTube appears to lend itself mainly to listening activities in a foreign language, but there are also reading and writing activities that can be improved using YouTube. This section lists two, but elements from the two can be expanded upon and blended with other reading and writing activities.

- Note-taking and summarizing: Although this activity could be used for high beginner and pre-intermediate level students, it works best for students at the intermediate level or above. The note-taking and summarizing activity requires students to use YouTube to listen to lectures on various topics, take notes on the main points and important details, verbally check and expand their notes with a partner, listen again to further expand their notes, and then write summaries from their notes. They can then look at a transcript of the clip and compare their summaries with those of their classmates and teachers. If the students' summaries differ considerably from the teacher's, then the teacher can point out why he or she chose the information included in the model summary. For example, by pointing out specific discourse markers that indicate an important piece of information in a text, teachers can illustrate what students could look for in future encounters with similar texts. A good source of speeches on a variety of topics is TED Talks. TED Talks are generally limited to less than 20 minutes and most have a transcript available at the TED Talks homepage (http://www.ted.com). While note-taking and summarizing are difficult to master, both are essential academic writing skills and necessary for numerous standardized proficiency tests. YouTube provides opportunities to practice these skills with engaging materials. A normal assessment of notes can be labor-intensive for the teacher as it involves checking which points have been included, understood, and formulated properly. A possible alternative to checking students' notes would be to do as Flowerdew suggests, and use tasks that require students to reintegrate knowledge from their notes, such as writing a short essay on the topic or giving a brief oral report that can instead be used for evaluation (Flowerdew, 1994). 
- "How-to" writing: The "how-to" paragraph (for beginners) or essay (intermediate to advanced) is a genre that lends itself well to the use of YouTube. The teacher first models the task for the students by choosing a video of appropriate length and complexity, writing a step by step guide to what is contained in the video, creating a cloze or sequencing activity, and having students complete the activity. Students are then instructed to find a video that interests them of similar length, complexity level, and topic. Next, students create their own cloze or sequencing activity. Finally, students exchange activities and try them out. It is easy for students to understand the genre of how-to videos and any skills learned will often be used receptively and productively in both real life and academic settings. Student assessment is based on accuracy of writing the important elements of the video.

World Englishes. As has been well documented (Seidlhofer, 2005), English has developed into a lingua franca for the modern world. In the early 1980s, Kachru coined the term "World Englishes" to describe the variety of Englishes that have developed (Kachru, 1992). One of the main goals of English language education is for students to communicate not only with native speakers but also with non-native speakers. Students exposed mainly to sanitized English in materials published for learners are often shocked when they encounter English in the real world and this shock is doubled if this English is not in the most standard American or British accent. One solution to this problem is to expose students to authentic English in as many dialects as possible.

YouTube is an ideal vehicle to teach World Englishes and expose students to a variety of English dialects. Short videos in various dialects are easy to access, and the variety of content and cultures is enjoyable to students. Whole film study can be rewarding for a dedicated class, but short clips allow for the largest variety of accents and situations to be experienced. There is a significant variety of activities possible; only a few will be detailed here.

- Current events and media study: One way for students of nearly any level to study World Englishes is to compare news clips about major world events, such as $9 / 11$, the earthquake and tsunami in Japan, or the British royal wedding of 2011. In this activity, the teacher chooses two clips about the same topic from different varieties of English, and then students watch and transcribe the clips. Afterward, students look at their transcriptions and the video and pick out key differences and similarities in focus, word choice, and pronunciation. They then can compare with a partner and add any relevant points they missed. The teacher shares his or her list of differences and explains why he or she included each point. Students are then encouraged to do the same task by themselves. They can be given a list of topics and clips to choose from prepared by the teacher or brainstorm their own topics and search for clips to fit the task themselves. As an assessment activity, students can make a presentation of their two clips, the differences they found, and why they chose those differences.

- Cultural entertainment study: This activity is best for higher-intermediate and advanced students, and it involves entertaining drama clips that demonstrate differences between cultures within the English-speaking world. In the activity, teachers prepare clips of dramas that are likely unfamiliar to most students. Since American television programs are generally the most popular throughout the world, short clips of Neighbours, EastEnders, and Coronation Street are great introductions to Australian and regional British English dialects. This activity is slightly more complicated, and has two primary phases followed by an assessment phase. 
- In the first phase, the teacher chooses a one- to three-minute clip from the chosen drama and prepares a transcription. The teacher then chooses vocabulary he or she thinks will be difficult and provides a word list and definitions. With the difficult words, the teacher prepares a vocabulary activity, a cloze activity, or a matching activity. The teacher writes comprehension questions on all the main points in the clip and discussion questions on the issues raised in the clip. Students do the vocabulary exercise and read the comprehension questions; they then watch the clip and answer the questions. Then they check with their partners to confirm understanding. The teacher confirms the correct answers and responds to any new student questions. The teacher finally introduces the discussion questions and the students discuss the issues they raise.

- In the second phase of the activity, students choose their own videos to present. The teacher can present students with a list of clips that are acceptable or students can search YouTube for clips. Finding English language entertainment clips from countries such as the U.S.A., the U.K., Canada, and New Zealand is much easier than finding similar clips from former colony countries such as India, Singapore, or Jamaica; however, it can be done. Once students have found a suitable clip, they create a transcript, vocabulary activities, comprehension questions, and discussion questions.

- For the assessment, the teacher checks their work and they present their clips and activities to small groups of classmates. Assessment is based on the accuracy and effectiveness of the activities the students prepared and presented to classmates.

\section{Conclusion}

EFL classes with access to the necessary technology can make good use of YouTube and other online video-streaming sites. However, it is important to realize that there are some limitations. First, YouTube is limited to what copyright restrictions allow. If students are determined to focus on certain clips that are not available on YouTube due to copyright infringement laws, then students will have to procure these clips on their own. Secondly, given the vastness of the YouTube library, a certain amount of structuring and guidance from the teacher might be necessary in order to prevent students from spending unproductive hours perusing the site. A third consideration teachers might need to take into account is the nature of much of the material on YouTube. Although the site does not allow nudity, there is a fair amount of risqué content and provocative language available. Teachers of younger students would be well advised to take this into account. Finally, certain countries have placed bans on YouTube and other video streaming sites (Toksabay, 2010), meaning that classes in those countries might have greater difficulty accessing useful online videos.

However, YouTube remains a valid resource for teachers seeking to enhance their lessons with lively, topical content, and further research into the use of the site (as well as other online video-streaming websites) would be very welcome for the EFL and SLA community. Further avenues for academic inquiry might include, but are not limited to, comparing different videostreaming sites for the type of content provided and technological advantages available or determining the degree to which students are already accustomed to YouTube and the frequency with which they use it. Additionally, YouTube clips in similar genres, but from different creators, might be compared for effectiveness. Finally, different video media--VHS, DVD, and YouTube--could be compared with each other with regard to the availability of content, the quality of data storage, ease of access, and student / teacher preference. 


\section{Author Note}

Jon Watkins, Intensive English Program, Kwansei Gakuin University, Hyogo, Japan, and Michael Wilkins, Department of English Education, Kansai University of International Studies, Osaka, Japan.

This article is based on a presentation given at CamTESOL 2011. The authors would like to thank Kansai University of International Studies for the financial support that made this presentation possible.

Correspondence concerning this article should be addressed to Jon Watkins. E-mail: admiral.jon@gmail.com

\section{References}

Benson, P., \& Voller, P. (1997). Autonomy and independence in language learning. London, England: Longman.

Berk, R. A. (2009). Multimedia teaching with video clips: TV, movies, YouTube, and mtvU in the college classroom. International Journal of Technology in Teaching and Learning. $5(1), 1-21$.

Cameron, J. (Director). (1997). Titanic [Motion picture]. US: Lightstorm Entertainment.

Flowerdew, J. (1994). Academic listening: Research perspectives. Cambridge, England: Cambridge University Press.

Graham, J. (2005, October 23). Webisodes return, now as advertising. USA Today. Retrieved from

http://www.usatoday.com/tech/news/techpolicy/business/2005-10-23-webisodes_x.htm

Johnson, R. K., \& Swain, M. (1997). Immersion education: International perspectives. Cambridge, England: Cambridge University Press.

Kachru, B. (1992). World Englishes: Approaches, issues and resources. Language Teaching, 25(1), 1-14. http://dx.doi.org/10.1017/S0261444800006583

Leung, A. (2004). Fostering learner autonomy among weak students via information technology. The HKU Scholars Hub. Retrieved from http://hdl.handle.net/10722/30657

Mangubhai, F. (2005). What can EFL teachers learn from immersion language teaching? Asian EFL Journal, 7(4), 203-212.

Seidlhofer, B. (2005). English as lingua franca. ELT Journal, 59(4), 339-341. http://dx.doi.org/10.1093/elt/cci064

Shea, D. P. (1995). Whole movies and engaged response in the Japanese university ESL classroom. In C. P. Casanave \& D. J. Simons (Eds.), Pedagogical perspectives on using films in foreign language classes. Retrieved from ERIC database. (ED423689)

Timeline. (2011). YouTube.com. Retrieved from http://www.youtube.com/t/press_timeline.

Toksabay, E. (2010, November 3). Turkey reinstates YouTube ban. Reuters.

Wang, L. (2005). The advantages of using technology in second language education: Technology integration in foreign language teaching demonstrates the shift from a behavioral to a constructivist learning approach. THE Journal, 32(10), 39-42. 